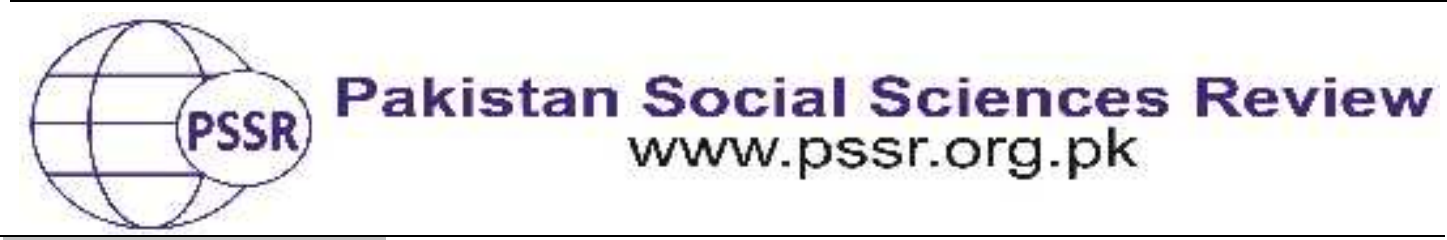

RESEARCH PAPER

\title{
China-Pakistan Economic Corridor: A Faircloughian Approach to CDA of International Print Media
}

\author{
Qaiser Sharif* ${ }^{1}$ Anila Sultana² Shazia Naseem ${ }^{3}$
}

1. Lecturer, Department of Humanities and Social Sciences, Nazeer Hussain University, Karachi, Sindh, Pakistan

2. Lecturer, Department of Economics, Federal Urdu University of Arts, Science \& Technology, Karachi, Sindh, Pakistan

3. M. Phil. Scholar, Department of Education, IQRA University Karachi, Sindh, Pakistan

\section{PAPER INFO}

Received:

March 09, 2021

Accepted:

May 01, 2021

Online:

May 15, 2021

Keywords:

CPEC,

Critical Discourse

Analysis,

Fairclough,

Perspectives

*Corresponding

Author

qaiser.sharif@nhu.

edu.pk

\section{ABSTRACT}

The aim of the present study is to analyze the antithetical roles of discourse narratives on CPEC that how they create unrest or pertinence of $\mathrm{CPEC}$ in changing the regional ties through international print media. China-Pakistan Economic Corridor (CPEC) played an instrumental role to form a close and firm tie between the neighboring countries which generated multiperspectives about this macro cross-regional project. The researcher randomly selected one international newspaper and two journals which are famous and unbiased for their political reviews. The researcher used Faircloughian approach to analyze these multi-perspectives expressed in international print media. The qualitative results of the study revealed that countries used the international print media to advocate their state policies and stance over the mega projects like CPEC which can be the game changer for any region.

\section{Introduction}

Pakistan shares its border with China in the North. By dint of Pakistan's geographical location in the region and access to the hot waters, China launched a mega project- China-Pakistan Economic Corridor (CPEC) in coalition with Pakistan. It is a mega development project which will be a game-changer from economic and geographical advancement perspective for both China and Pakistan. From the broader perspective, it will not only provide a rout for China to the Arabian sea and Indian Ocean to expand her export and access to the African countries, rather it will also produce so many businesses and job opportunities for the public of Pakistan. It will bring a great advancement in economic growth in Pakistan. The economic growth in the region, especially in subcontinent, is the hallmark of this project. However, the project is not restricted between China and Pakistan rather both the countries have shown their interest to expand it to the South Asian states. CPEC has become a multilateral project in the region. On realizing its blessings, many other 
countries like Iran and Russian and central Asian states have also displayed a considerable interest in the project, though Pakistan would remain the center of interest because of China's geo-strategic plans and goals.

Many economists and strategists have declared CPEC as a flagship mega project which will help China and Pakistan to determine and envision the mutual benefits. The scope of these benefits is not limited to subcontinent rather its branches have been enrooting across the region. CPEC will help both the countries to increase a considerable dominance around the world. This is why, the strategists and analyst called CPEC a game changer project.

The relationship between both the countries is not a newfangled rather it is rooted back to the time of Pakistan's recognition of China with her creation on the world globe. Moreover, Pakistan has had advocated the stance and foreign policies of China at any forum, especially in United Nation General Assembly- a common floor for all the nations. Therefore, the legacy of their relationship has gained high mutual trustworthiness and credibility that is strengthening their bond of friendship with each passing day. According to Khan (2014), the strong relationship between both the countries made the path easier for China to obtain a strong position in world politics and attaining a permanent membership of United Nation Security Council.

The coalition between Pakistan and China entered into the practical relationship with the advent of the Karakorum Highway $(\mathrm{KKH})$. The project was completed in 1970s that established an alliance for the trade of both the countries. The Karakorum Highway became more significant at the back of CPEC which improved its functionality and usability. LiKegiang, Prime Minister of China, expressed that (reported in The Nation, 2013);to support Pakistan is all in the favor of China itself, as it will boost the economy of both the countries. This promise came up with the concrete manifestation of CPEC in the region.

This flagship project started with the investments of US $\$ 46$ billion with no determined end. In this regard, "Belt and Road" (B\& R) development framework of China is playing a pivotal role. CPEC has introduced a big setup of energy producing plants, roads, railway transportations, and pipelines that will possibly stretched over $3000 \mathrm{Km}$. The opening of Gwadar Port in Blochistan is the first step into the economic growth in the region. The resources will be shifted from the developed provinces like Xinjiang to Blochistan as underdeveloped province in Pakistan. Such shifting of resources amongst the underdeveloped provinces will lessen the income gap and produce opportunities for all equally.

CPEC will also expedite China's economic growth by creating opportunities to access the global industry and trade market. It will open many new vistas of business and exports for China. It will also reduce China's dependency on regional and limited export. China will easily get access to the world markets. Moreover, China will also be able to get access to the cheap oil from Africa and Middle East 
countries for its import in China. Such cheap imports will optimize the performance of China's industry as it can be easily transported from Gwadar to the nearby province of China. For that very purpose, China and Pakistan spread a vast network of roads within their region and some ports to Africa, Europe and Asia. It will improve the connectivity and functionality of the project amongst the states.

To meet the challenges and demands of CPEC project, it is mandatory for Pakistan to develop its utmost indigenous abilities in energy production. To enhance it power capacities, Pakistan has to take the foreign assistance. By keeping the modern requisites of the project, a big portion of the project is spared for energy production. In this regard some coal-based power production plants are also installed along with the hydro-power, wind power, and solar power projects. Such addition to the Belt \& Road project has many fold benefits for Pakistan. It will make the country self-reliant in power and electricity production and help to reduce a considerable amount of energy deficit throughout the country. Such indigenous projects will bring more autonomy and sustainability in internal affairs of the state. Therefore, at many formats, CPEC will create a win-win position for both the countries.

Yousaf (2012) noted that strategically and geographically, Gwadar Port has a great significance because it is situated in Balochistan (Pakistan), touching with the border of Afghanistan. Additionally, the border of Iran is also much closed that is just 100 kilometers away from the port. Moreover, the strait of Hormuz that has a plenty of oil reserves is just 400 kilometers away from Gwadar. The initial Chinese investment in Gwadar was 1.62 billion USD to make it operational for the next 40 years. The infrastructural and industrial development of the port includes international airport, macro markets, technology hub and expressways.

To highlight the significance of this project, many countries added up their perceptions and concerns through international print media. Their narratives through international print media depict their state policies and views. The aim of this paper is to analyze the discourse by the different countries to shape the minds and thoughts of the masses through international print media. The study includes the following two major questions to explore the impact of international print media on shaping the mindset of common masses;

\section{Literature Review}

Critical discourse analysis was introduced in twentieth century and its foundations originated from Critical Linguistics in later of the century. Fowler et al., (1979) noted that the proper use of discourse analysis was originally developed by the critical linguistics in England in 1970s. They further coded that "the connection among language structure and social structures is very strong" (p.185). He further said that language is instrumental for social structures (p.189). This is how the Systemic Functional Linguistics paved the ways for discourse analysis. DA elaborates that how the social and personal procedures are intervened through different forms of texts. Halliday (1979) noted that any text is not just the product 
rather it is also a process which can be created, developed and integrated in that particular context.

By the end of twentieth century, the famous linguist and scholars like Fairclough along with Van. Dijk added the word "Critical" with "Discourse Analysis". It all happened because of scope of critical linguistics that was broadened and a new term emerged as "Critical Discourse Analysis". Fairclough (1995) highlighted the two major issues in the study of Critical Linguistics as the "interpretive practices of audiences" were left ignored. In fact, the previous studies of CL highlighted that the interpretations of audience and authors are same which is quite similar to the interpretations of analysts. Moreover, Fairclough(1995) also highlighted another issue that earlier CL failed to notice the "intertextual analysis of text".

Fairclough (1995) claimed that apparently the linguistic analyses were more inclined towards the study of clauses that ignored to draw the attention towards the higher-level characteristics of text.Zahoor (2005) studied the political and social changes from different perspectives especially from Faircloughian approach.Entman (2004) suggested that few aspects of an issue, which clearly display the relationship between both the aspects,would propose the particular explanation with remedy for that very issue.

\section{Ideology through Discourse: a Discursive Relationship}

Widdowson (2000), said that "Critical Discourse Analysis is an attempt to unveil the hidden ideologies in the texts". Many linguists have attached the term "ideology" with Critical Discourse Analysis that enhances its significance in the practical field. Hodge and Kress (1993) claimed that, ideologies are the reflection of our social realities. Van. Dijk (1997) pointed out the answer for "what are the aspects which contains the different ideologies in their texts. Fairclough (1989) added the term "critical" to enhance the scope of the issue by highlighting the fact that hidden agenda or the ideology is the instrumental focus of any text.

It is noticed that masses have different perceptions and outlooks towards their societies and communities where they are living. These outlooks and perceptions define their ideology. Fairclough called it their "Hidden Agenda" because people talk about it covertly not overtly in the text.

To sum up, it can be declared that the text displays the ideology of society or community if it is analyzed through CDA frameworks. However, it is claimed that ideology gets firms roots when it is shaped into invisible. On the other hand, when any ideology is commonly perceived, then the discourse turns into neutral state. Therefore, the words of everyday talk unconsciously become normal. Ideology plays a vital role to transform the identities and shape the outer world. 


\section{Material and Methods}

The theme of the present study demands qualitative approach. Therefore, the qualitative research method is opted for the study to analyze the perceptions of political, economist and strategists narrated in the international print media. Lincoln (2000) believes that, qualitative approach is the most appropriate when scholars endeavor to examine the perceptions, ideologies, values and opinion over any stance and policy. As the present study deals with the perceptions, opinions, and objectives, qualitative research is the effective method to collect and analyze information. Moreover, qualitative research favors the flexible data interpretation.

Researcher selected one newspaper, Al-Jazeera and two political review journals, Eurasia Review and Modern Diplomacy from international print media randomly. All these data collection resources have plenty of discussion through article published by the time and again. The stretch of speeches and opinions of the political heads were carefully selected which solely qualified the research objectives.

\section{Research Framework}

\section{Fairclough's Model}

Norman Fairclough is a known scholar in the field of CDA who single handedly introduce the relationship among "language, power, and ideology". It was, initially, introduced in 1989 and this model was revised later in 1995. His model is the center of constellation of CDAframeworks. The credit to introduced the practical theoretical framework for CDA goes to Norman Fairclough.This theoretical framework provided the sufficient guidelines to interpret any text. Fairclough's model of CDA includes three main process-step for textual interpretation; text, the object of analysis; interpretation, a framework to highlight the object of the text; and explanation, the background, which develop the context for socio-historical practices. In CDA, all the steps or stages must beanalyzed separately.These stages which became the part of this study in the next chapter are;

i) Text Analysis for description

ii) Processing Analysis of the text for Interpretation

iii) Social Analysis for the explanation rationale of historical background and context of text

\section{Results and Discussion}

\section{Discourse Narratives to Create Unrest around the World}

"... all the allied forces with the U.S. are at unrest state of mind about the swift growth and worldwide recognition of the BRI. Resultantly, this unsettling mindset is spreading a propaganda to sabotage the esteem and essence of the project. China's Nation is going to cripple the economy of Pakistan. In other sense, 
CPEC will be another East-India Company in subcontinent. Such discourse narratives will misguide the novice mind around the world to inculcate the propaganda against Pakistan and China."

"Also, it has been claimed that Chinese are highly proactive to attain some other imperial goals which are evident from China's history. China is not among the exponents of mercantilism. The analysts believe that China is not doing just to uplift the condition of the region rather they looking for some of their own hidden benefits. The condition of Pakistan would not be much different from the African countries as it is already manipulated by China.In addition, it is evident from the current state of the country like Pakistan that it might be in debt to China. Yet, it cannot be overruled that Pakistan is a sovereign state and fully autonomous to formulate its policies without taking any foreign dictation".

“...on some occasions, a Former Ambassador Abdul RazakDaood, and Shah Mahmood Qureshi (a Foreign Minister), declared that CPEC is moving in the right course and it cannot be matched to a debt trap, rather it is a project of concord, opulence, progress and job establishment for Pakistan".

\section{Textual Analysis}

The US narrative against CPEC is quite clear in the first report as its representatives used very shocking words to change the minds of masses even the public of Pakistan. They called it "a dent to the Pakistani economy" or "CPEC is heading towards another East-India Company". Their unrest is visible through their selection of words and phrases like "China pursuing imperial goals" and "debt trap". The case is tried to be intensified through the use of phrases like "military dimensions"

\section{Interpretation}

All the newspapers and political and democracy journals used a typical language to highlight the issue and create a unique effect on the minds of their readers. By reading such news and articles people transform their beliefs in the targeted ways. A considerable amount of US-India jealousy can be noticed through close interpretations of above-mentioned chunks of news.

\section{Explanation}

The immediate condition which resulted into the production of such utterances by the US and India highlights that these countries are not happy with the geographical ties and developments. They are insecure because they can analyze that their economy might face downfall because of this mega project and coalition. Therefore, they manipulated the international media to raise the voice against CPEC as well as to change the minds of people. 


\section{CPEC Building Relationship with Neighboring Countries}

"It is a reality, that Tehran is rich in natural resources, and its geographical location which makes it important in the context of connectivity in South Asia and Central Asia (especially in the context of the China Pakistan Economic Corridor CPEC)."

"The Iranian Foreign Minister also made the point, that Tehran was exploring participation in the CPEC. In May 2019, Iran had mooted the idea of connecting Chabahar Port with Gwadar."

"I offered and invited Prime Minster Imran to come and visit our country to strengthen the relationship and to expand the trust on order to move forward,"

“Islamabad's decision to invite Iran to join CPEC, clearly reiterates Iran's crucial location. It remains to be seen, how the Tehran-Islamabad-New Delhi trilateral will work out in the near future."

"India, Pakistan, Afghanistan and Iran can join hands. Such connectivity need not be under the rubric of CPEC, but could be driven by Pakistan providing land access to India to Afghanistan and Central Asia".

"In order to link the states of Middle East and Africa linked through Gwadar port, China has invested $\$ 46 \mathrm{bn}$ in this project and looking forward to establish a sound economical work ground.

\section{Textual Analysis}

A clear determination for a strong bond amongst the regional states by China can be witnessed in its statements and practical approaches. China's role to develop a strong bond is fully determined through the selection of the words like "promises", "destined", "regional connectivity and integration", "exploring participation", "peace in the region" and "the Tehran-Islamabad-New Delhi trilateral". The selection of the words and structure of the phrases show a clear state of mind of the speakers towards the ultimate goal.

\section{Interpretation}

Most of the words are hyphenated to show a structural as well as a practical interpretation of the theme of multi-state bond and joining of hands in the project. The structure of the text develops a sense of tie in the minds of the readers as well.

\section{Explanation}

All the chunks of the news articles create a harmony in the minds of the readers. The scope and address of the narrative is quite wide. The scope covers multiple society by highlighting their immediate benefits. The discourse shows that it is a multidimensional project which shares so many advantages for dynamic 
societies. All the communities from India, Pakistan, Afghanistan, and Iran can join the mainstream of this project. Even the states from East-Asia are also invited.

\section{CPEC as an Opportunity to Utilize Human Resources}

"A vast pool of around 20,000 China-graduates in Engineering, Agriculture, Health Sciences, Environmental Sciences, Economics, Management Sciences, Social and Natural Sciences are available in Pakistan readily".

"China graduates are the human resource required for CPEC, as they understand China in addition to their professional qualification".

"Ambassador Yao Jing is a sincere friend of Pakistan; his advice carries highvalue and may be taken seriously. Especially while we are entering into the SecondPhase of CPEC, where the private sector may be involved in Industrialization, Agricultural Sector, and Services Sector, China experts can play an instrumental role and maximize benefits for Pakistan".

"The CPEC, the analysts declared that, is a prized prospect for Pakistan to appreciate its strategic and economic latent and is considered as a "Game Changer" for Pakistan and the region".

\section{Textual Analysis}

The selection of words and phrases like,"a vast pool", "graduates", "highvalue", "Industrialization, Agricultural Sector, and Services Sector", "CPEC is a prized opportunity" and "Game Changer" shows that discourse of the news is especially designed to grab the attention of the population in the specific region. China has put a specific emphasis on the youth to be utilized in productive way. To create the interest for fresh graduate, different narratives are made in the international media.

\section{Interpretation}

The text contains highly effective structure that clarifies goal of the discourse. The text creates a unique discourse that attracts the audience in a very explicit way. The addressers directly invited the addressee without any implicit call.

\section{Explanation}

The discourse forms a lucid relationship with social and cultural reality. In all the countries, whenever any new project is launched, the youth of that country make some hopes to occupy some positions to exploit their skills. Similarly, this is mega project which can accommodate so many skilled people by securing their future careers as it is a never-ending project. 


\section{Perspective on Fluctuating Dynamics in South-Asia}

"Ensuring that Pakistan does not snuggle up too much to Iran has become even more crucial for Saudi Arabia as it seeks after Jamal Khashoggi's death to enhance its indispensability to Trump's effort to isolate and cripple Iran economically". (Al-Jazeera)

"By dint of Pakistan's position in the region, strategically sound with diverse natural resources and holding atom bomb, it is quite appealing for Pakistan to take a leap to establish its economy by utilizing its natural resources at optimum level".

"China and Russia are particularly working to enhance their influence in Eurasian region. Because of this endeavor, The US considering it a threat for its role of being a global leader. To mitigate the intensity of their influence, the US is attempting for some tactics halt the progress in the present century from becoming the Asian century".

"Therefore, the economists are calling this project as a game changer that will affect the progress and growth of the US".

"Pakistan is developing its relationship with the neighboring countries especially with Iran, China and the Middle East states. It will not only develop their economies rather it will enhance and improve their ties with eachother. It will create many opportunities to move across the border for job seeking".

\section{Textual Analyses}

The above-mentioned chunks of the articles and news have a special diction that suits to the art of news writing. The words and phrases are carefully chosen. For instance, "newly arising partnerships and rivalries", "the power centers are shifting", "the US efforts to sequester and demolish Iran economically", "rapidly altering dynamics", etc creates a unique but horrifying effect on the mind of the readers. All the phrases depict a clear ideology of military alliance in the region. Word choice is misleading in this context.

\section{Interpretation}

The text has a unifying effect that creates a discourse of its own type. The structure of the text develops a threatening discourse that appeals the military analyst around the world. All the terms are quite appealing and structure enjoys the advantage persuasiveness. Moreover, China's direct call for the countries for the coalition is an explicit threat to the fake prude sovereignty of the US. On the other hand, the discourse is also an appeal to the regional countries for joining hands for industrial and technological growth in the region. 


\section{Explanation}

The pandemic disturbed so many projects around the world. Many companies drew back their labors and shares because clear decline in the progress. In such situation, many coalitions got broken and new were formed too. Iran left the block of India and expressed her wish to join Pak-China block. China and Russia grew their influence in Eurasia and Pakistan enjoying its autonomy in the region. The discourse in the above-mentioned excerpts shows that the US is feeling isolated and reckoning a severe threat to its economy.

\section{Conclusion}

After analyzing the multiple excerpts from different international newspaper and analytical journals through the lens of Faircloughian approach, it is manifested that all the discourse narratives have a reflective ideology. Different nations have different hidden interests and intentions whether to converge the masses from a point or to attract them on the point of their favor. However, the results qualify the objectives of the study that international media played a pivotal role to project the image of CPEC through its news discourse. It also highlighted the major constituents of the project which bother the US and India, especially, economic growth and military alliance. In the last, the study focused on the stance of the allied countries through international media that how the project is significant for the economic growth and institutional development in the region. The different perspectives by the different nations are collected which are analyzed through the approach of Fairclough model. However, the stance of different stakeholders is reinforced through multiple sources and reports in international print media. 


\section{References}

China and BRI, CPEC Narratives - OpEd. (2019, May 01). https://www.eurasiareview.com

CPEC: Geo-strategic and economic significance. (2018, February 25). https://studies.aljazeera.net

CPEC: Pakistan and China strengthen economic ties (2016, November 12). https://studies.aljazeera.net

CPEC: Whether a Debt Trap for Pakistan or Not? (2020, May 22). https://moderndiplomacy.eu

Dijk, V. T. (1983). Discourse analysis: Its development and application to the structure of news. Journal of Communication 33(2), 20-43.

Entman, M.R.(2004). Projections of power: Framing news, public opinion, and U.S.foreign policy,' Chicago: The University of Chicago Press.

Halliday, M.A.K. (1994). An Introduction to Functional Grammar (2nd Ed). London: Edward Arnold.

Imran Khan CPEC Diplomacy: Remodelling Trade Politics between Pakistan, Iran, Saudi Arabia and China. (2108, October 29). https:/ / studies.aljazeera.net

Iran, CPEC and regional connectivity. (2019, December 12) Modern Diplomacy. https://moderndiplomacy.eu

Khan, M. (2014, January 20). Mutuality in Pak-China relationship. Pakistan Observer. p.24

Multiperspectives on altering dynamics in the South Asian region and Challenges for CPEC. (2020, September 13). https:/ / moderndiplomacy.eu

Pakistan can maximize the benefits of CPEC by involving China experts. (2020, September 27). https:/ / moderndiplomacy.eu

The CPEC and US-India Enviousness. (2018, Jan 18) Modern Diplomacy. https://moderndiplomacy.eu

The 'Eurasian Corridor': CPEC - Catalyzing Regional Connectivity and Integration. (2020, May 03). https:/ / moderndiplomacy.eu

Van Dijk, (1990). The Growth of Discourse Analysis, Discourse and Society: A New Journal for a new Research Focus, 1(1) 5-16) 
Yousaf, A.T. (2012). Is Gwadar Port an economic haven for Balochistan and Pakistan? https://ehl.lu.se

Zahoor, A. (2015). Kamila Shamsie's Novel "Burnt Shadows": A Discourse of Traumatic displacement: Published by European Centre for Research Training and Development UK 